\title{
Analysis of robotics industrial manufacture \& promotion of artificial intelligence
}

\author{
Aneel Ahmed ${ }^{1 *}$, Hamza Karamatullah ${ }^{2}$, Asil Budhwani ${ }^{3}$ \\ 1, 2, 3 Shaheed Zulfiqar Ali Bhutto Institute of Science and Technology, Karachi, Pakistan
}

\section{Keywords \\ Artificial Intelligence (AI) Replacement of human labor Industrial automized Advancement of efficiencies Possibilities and limitations Integration \\ Intelligent machinery}

Received: 5 September 2019 Accepted: 7 November 2019 Published: 12 February 2020

\begin{abstract}
The present age is the age of science and innovation. Robots have long borne the planned to conquer any hindrance between the automized world (the web of things) and the physical world. As the most reassuring possibility to subject the following major modern upset after the present third (computerized) mechanical upheaval, apply autonomy is set to play an ever progressively huge job in the public arena for its impact in each part of life. Counting prescription and medicinal services, building administration, fabricating, nourishment creation, coordination and transportation. The present century is likewise the century for Asia, or more noteworthy China specifically. China has turned into the greatest and quickest creating nation in the worldwide modern robot showcase for its changing assembling condition and improving nature of-expectations for everyday comforts, with anticipatable interest of robots in the assembling business, yet in addition other administration and societal segments. With its solid convention in innovation and close connections to overall research wildernesses, Hong Kong at present holds a main edge in parts, for example, medicinal, coordination, and household administration robots. Not with standing, with its total size, money related duty, and solid modern establishment, the Terrain is quickly grabbing pace, particularly in the mechanical and amusement divisions. It is subsequently a basic minute for scientists to join endeavors and structure a minimum amount in automated research to keep up the provincial, and towards overall lead in administration mechanical research. Hong Kong analysts, chipping away at the front line of mechanical autonomy that is intently connected with the future economy. Have many top-level work for mechanical careful help, call the board, assembling, and warehousing the executives, prompting exceedingly translational and gainful results that would help build up and flourish the Hong Kong one of a kind industry in restorative and administration robots, supplemented by a huge creation center and great market in the Territory. After deep study about the countries who are well developed in robotic world. We can have summed up with an idea that those countries who are using technology from this modern age are not only just getting advantage also building their national character amongst the other nation.it becomes mandatory to make our generation acknowledgement about this global automized technology and provides the platform to the industry to use such robotic autonomous system so that under developing countries should take advantage from them. Today the technology which is very popular amongst the scientific society according to latest research is the knowledge of AI. Inspire from NASA we research about the latest technology beneficial for human beings come up with an idea that as far the question of Industrial manufacturing is concerned we all know that accuracy and quality of work is possible through the machinery as compare the human work is referencing.
\end{abstract}

(C) 2020 The Author(s). Published by TAF Publishing.

\section{INTRODUCTION}

The overview of this research paper come up with an idea that we all know that the present century is all about science and technology. If we are not using the technology, we are lacking our skills because majority of the countries taking advantages of the present invention and new exploration making it possible to easily implement the ideas of advancement. Just like the brand companies of Mercedes Benz and Audi did. They are using fully automized and Robotics system to explore new feature in each new model of car. Just because they are using fully robotics system it doesn't mean that they harm the human labor actually this is the fact we

\footnotetext{
${ }^{*}$ Corresponding author: Aneel Ahmed

†email: aneel@szabist.edu.pk
} 
all know the quality of work and productivity of human and robot. Robot works efficiently without making mistakes. Also productive work is the output with less time with low maintenance cost. Overall if we estimate the budget of the salaries paid to the employs of the company per annum will much higher as compare to the cost maintenance of the Robots. Basically AI works with perfection with low cost. That's the reason why the world is working on AI. It seems that Robotics Engineering becomes the requirement of this modern day world. Apply autonomy is a part of building and science that incorporates gadgets designing, mechanical designing and software engineering, etc. This branch manages to the plan, development, and use to control robots, tangible criticism and data preparing. These are a few innovations which will supplant people and human exercises tin coming years. These robots are intended to be utilized for any reason yet these are utilizing for the conditions like bomb identification, deactivation to different bombs and so forth robots can take any frame yet a significant number of them have given the human appearance. The robots which have appeared as human appearance may prone to have the discussion like people, discourse, and acknowledgment and above all every one of the things done simply like the human can two. A large portion of the robots today tare propelled essentially and tare known as bio-enlivened robots.

Robots will not harm human beings in any condition based on how you assign the given task.

- Robots will follow commands given by humans without breaking law one.

- Robots will guard themselves without breaking other rules.

\section{METHODOLOGY}

\section{A. Appearance}

Robots have a physical body it depends on the manufacturer what he wants from their invention.. They are held by the structure of their body and are moved by their mechanical parts. Without appearance, robots will be just a software program [1].

\section{B. Brain}

Another name of brain in robots is On-board control unit. Using this robot receive information and sends commands as output. With his control component robot knows whato do else it will be just a remote-controlled machine [1].

\section{Sensors}

The utilization of these sensors in robots is to accumulate data from the outside world and send it to Mind. Funda- mentally, these sensors have circuits in them that creates the voltage in them [1].

\section{Actuators}

The robots move and the parts with the assistance of these robots move is called Actuators. A few instances of actuators are engines, and blower etc. The mind advises these actuators when and how to react or move [1].

\section{E. Program}

Robots just works or reacts to the guidelines which are given to them as a program. These projects possibly advise the cerebrum when to perform which task like when to move, produce sounds and so forth. These projects just advise the robot how to utilize sensors information to decide [1].

\section{F. Behavior}

Robots conduct is chosen by the program which has been worked for it. When the robot begins making the development, one can without much of a stretch tell which sort of program is being introduced inside the robot [1].

Before we can receive the rewards of complete automated coordination, we right now face the obstacle of getting robots out into this present reality-into homes, work environments, institutional settings, and open conditions. To do this will expect us to structure robots that furnish their clients with important connections that offer worth, to fabricate frameworks that are adequately powerful to work in reality, and to think about the long haul, genuine associations with them," says Educator Mutlu. In light of the test, the Human-Automated Communication area gives a head distributing setting to a quickly developing examination network. Inviting examination from the fields of mechanical autonomy and simulated intelligence just as in application spaces, including training, wellbeing, assembling, and tasks, the segment will concentrate on all regions of humanrobot communication inquire about that makes experimental, plan, specialized, or hypothetical commitments. "My primary point as Boss Manager is to see the segment remain at the forefront of research in issues encompassing humanrobot cooperation and related subjects," features Educator Mutlu. "Tending to the key difficulties in human-robot cooperation, including getting robots out into this present reality, will expect us to draw in and connect with various insightful networks and to make an interpretation of our discoveries into useful learning that will be utilized by industry. Open Access is vital to this degree of commitment and to the dispersal of our work to experts." 


\section{THE EFFECT OF AI AND MECHANICAL AUTONOMY ON WORK}

Openings have consistently been a theme of much theory. With regards to arranging and controlling information, handling complex numerical issues, and executing errands in a matter of moments, AI and apply autonomy are the most favored decision. Accordingly, computer based intelligence has entered pretty much every industry, from development, transport, and assembling to business knowledge, instruction, and medicinal services. It is, in this manner, not astonishing that numerous Silicon Valley figures, including Facebook Chief Imprint Zuckerberg, accept that not exclusively can man-made reasoning help and upgrade existing occupations, however it can likewise make new jobs.

\section{A. Need of New Jobs Roles}

The computer based intelligence and apply autonomy part never neglects to dazzle individuals with advancements. Assignments that used to be viewed as very intricate until already have presently been rendered basic, along these lines giving experts a more extensive space to concentrate on other tasks. In an ongoing report directed by Cap Gemini, almost 80 percent of the 1,000 associations who execute man-made reasoning have expressed that they would procure man-made intelligence and apply autonomy experts for new position jobs. Requirement for prepared experts: The effect of computer based intelligence and mechanical autonomy on business goes far more profound than simply work creation. Computer based intelligence, and in this manner, mechanical autonomy, are specialty innovations that request a broad comprehension of each related parameter. Concurring to industry gauges, the year 2018 confronted noteworthy work deficiencies in the innovation area. To such an extent that for 500,000 open engineer positions in the U.S alone, there were under 50,000 PC graduates to fulfill the interest. A study led by Salesforce Research stated that 52 percent of IT selection representatives confronted a noteworthy aptitude hole in their associations [2].

\section{B. Innovative Job Roles}

In an examination directed by Michael Page on experts about the effect of simulated intelligence and mechanical autonomy in their industry, most of study takers were anticipating computer based intelligence creating progressively inventive and energizing occupation jobs. Moved by these advancements, ventures would employ all the more profoundly talented individuals to design, create, and keep up associated and integral items [2].

\section{Training, Research, and Development}

Similarly as with each other innovation, man-made intelligence and robotics will thrive just through development. At the point when evaluated from a naturally visible perspective, the industry is still at a critical stage, and yet to be found and actualized. As mechanical autonomy advances to an ever increasing number of regions of human insight and undertakings, innovative work to more readily consummate automated models are especially sought after [2].

The eventual fate of most enterprises is overwhelmed by improvement of mechanical autonomy and AI. Working environments will turn out to be progressively productive, and the manner in which ventures direct their organizations is without a doubt expected to improve. It is, in this way, as ideal a period as any for computer based intelligence and apply autonomy experts to force how these advances will affect greater work openings. Rather than the dread of machines assuming control over occupations, computer based intelligence and mechanical autonomy are rather ready to make new and additionally energizing occupation job, in this manner altogether improving the work prospects of individuals in IT, yet in pretty much every industry [3].

\section{THE EFFECT OF MECHANICAL INNOVATION IN THE ASSEMBLING BUSINESS}

Efficiency and execution are huge parts to any compelling workplace. Time is gainful, and one imperative impact of the extension to robots as for time is the likelihood that robots can be tweaked to fit any schedule. They can continue running on hours that don't usually fit into a human agent's arrangement, and can essentially work throughout the day, consistently. This intensifies the usage of time and benefit. Since robots can move quickly and capably, there would be a phenomenal diminishing of slip-ups that could possibly be made by a human hand. Playing out various undertakings, which may be hard for human delegates to complete without submitting blunders, should adequately be conceivable by robots, which will crash the necessity for extra, less capable device. This considers a predictable movement of age that will propel gainfulness and capability [4]. Robots in the workplace progresses a greener circumstance. There is a creating eagerness for green gathering all around the world. To be "green" means imperativeness adequacy and earth friendly collecting structures. By overriding gathering floor workers with robots, nature inside the mechanical office can change. Since there are never again individuals working, there don't should be any rules on the temperature inside the handling plant, or whether the lights are on or off. By lessening essentialness including cooling, 
warmth and lighting the workplace, a greener workplace will be progressed [4].

\section{REVIEW AND HYPOTHESIS DEVELOPMENT}

The conceptual framework of this current study was drawn from two theoretical models (i.e., Uses and Gratification theory and Technology Acceptance model). Each of the models is elaborated in turns in the subsequent parts.
H1: Perceived industrial benefits of intramural inventions will positively affect the increasing growth of industry.

H2: Quality of production and man faction using latest robotized technology will have a positive influence on industrial income and growth of promotion.

H3: The door of Employment Opportunities is open for all as the rate of research and impact of technology increases. Leads the positive impact.

TABLE 1

DEGREE OR LEVEL OF ACTIVITY [5]

\begin{tabular}{lllll}
\hline \hline Key Robotics Products & USA & Japan & Korea & Eurpe \\
\hline Robotics Vehicles: Military and Civilians & Very Good & Fair & Fair & Fair \\
Space Robotics & Good & Fair & Not Applicable & Good \\
Humanoids & Fair & Excellent & Very Good & Fair \\
Industrial Robotics: Manufacturing & Fair & Excellent & Fair & Very Good \\
Service Robotics: Non-Manufacturing & Good & Good & Very Good & Good \\
Personal Robotics: Home & Fair & Excellent & Very Good & Fair \\
Biological and Biomedical Applications & Very Good & Fair & Fair & Very Good \\
\hline \hline
\end{tabular}

\section{The UK ranks $22^{\text {nd }}$ worldwide with a density of 85 units}

IFR

International Federation of Robotics

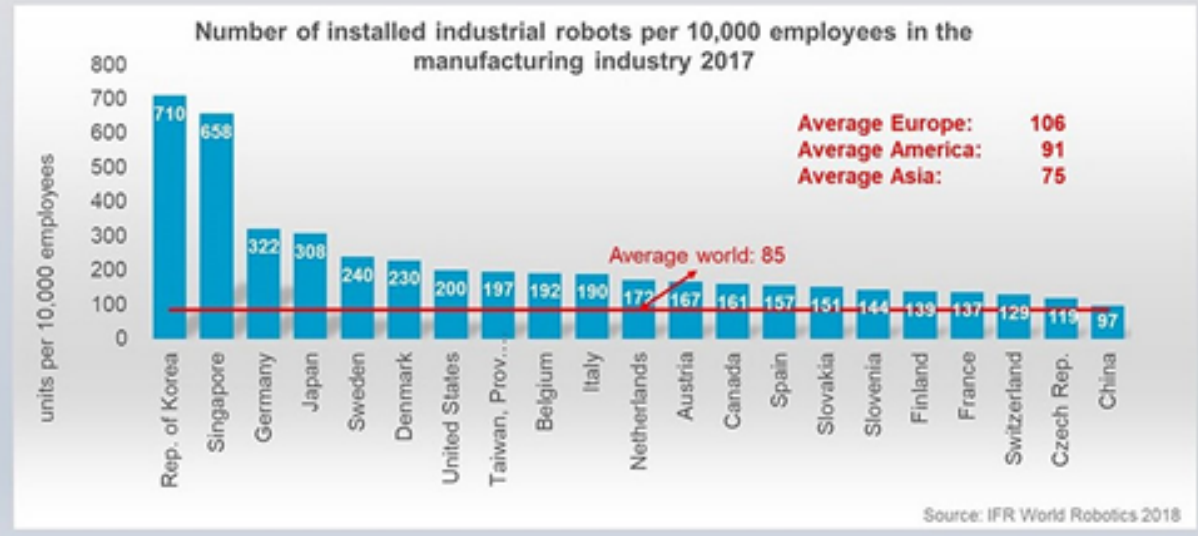

Fig. 1. Ranking of robotics worldwide [6]

\section{TYPES OF ROBOTS(BENEFICIAL FOR INDUSTRIAL MANUFACTURING)}

These are some types of robots given below:

\section{A. Articulated}

The component of this robot is its rotational joints and scope of these are from 2 to at least 10 joints. The arm is associated with the rotating joint and each joint is known as the hub which gives a scope of developments [4].

\section{B. Cartesian}

These are otherwise called gantry robots. These have three joints which utilize the Cartesian facilitate framework $\mathrm{x}, \mathrm{y}, \mathrm{z}$. These robots are given joined wrists to give rotatory movement [4].

\section{Cylindrical}

These sorts of robots have at any rate one rotatory joints which are utilized to associate the links. The utilization of 
rotatory joints is to pivot along the hub used to give direct movement [4].

\section{Polar}

These are otherwise called circular robots. The arm is associated with base with a contorting joint and have a blend of 2 rotatory joint and one straight joint [4].

\section{E. Scara}

These robots are predominantly utilized in gathering applications. Its arm is in round and hollow in plan. It has two parallel joints which are utilized to give consistence in one chose plane [4].

\section{F. Delta}

The structure of these robots resemble insect shaped. They are worked by joint parallelograms that are associated with the basic base. The parallelogram moves in a vault molded work area. These are primarily utilized in nourishment and electrical ventures [4].

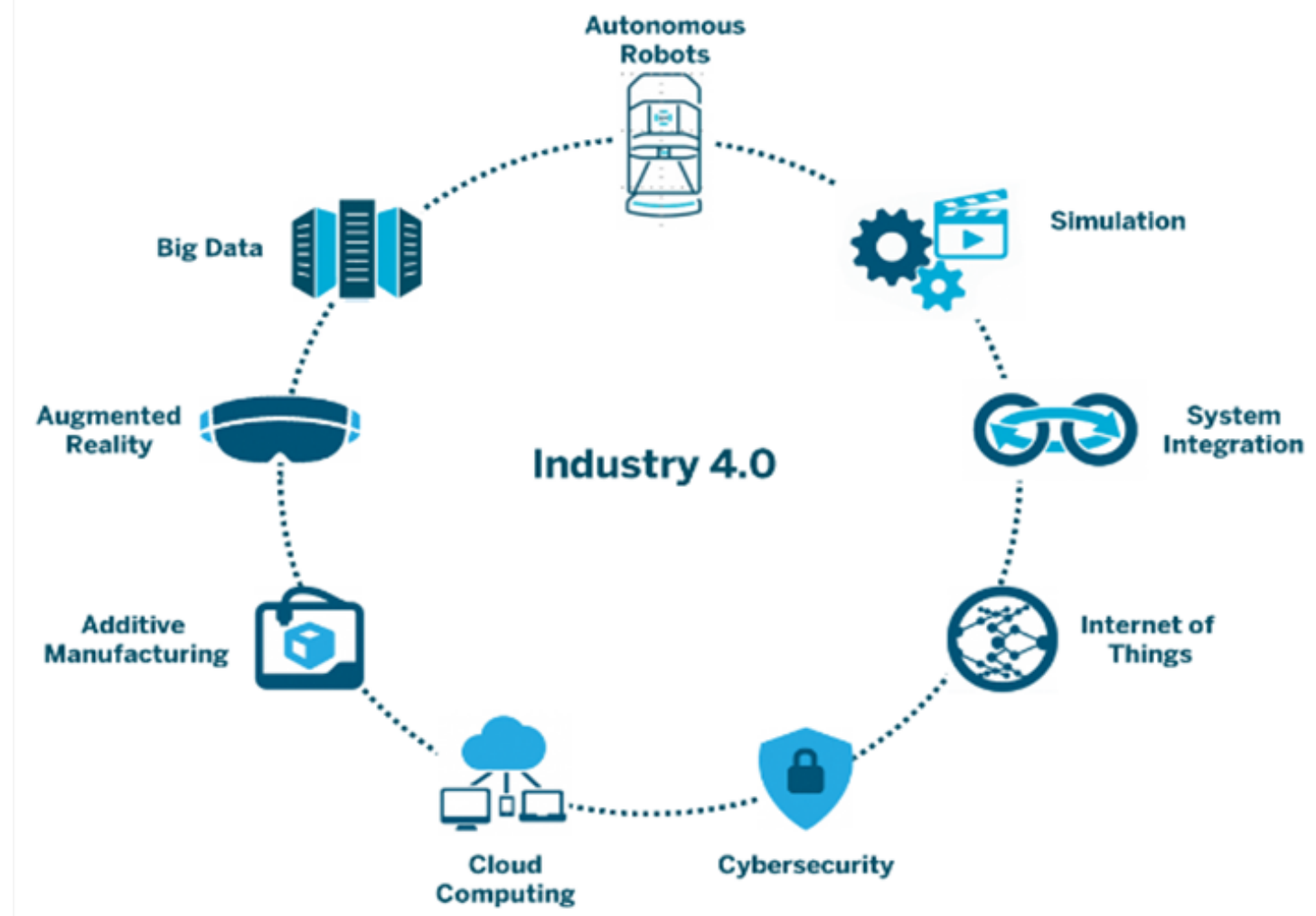

Fig. 2. Industrial Analysis of Robotics [7]

\section{ANALYSIS}

The development rendition of machines are robots which are utilized to do propelled assignments and are customized to settle on choices all alone. At the point when a robot is structured the most significant thing to be remembered is that what the capacity is to be performed and what are the confinements of the robot. Every robot has an essential degree of unpredictability and every one of the levels has the extension which confines the capacities that are to be performed [8].

\section{A. Adavantages}

The upsides of utilizing robots are given underneath: • They can get data that a human can't get [9].

- They can perform undertakings with no missteps and all around effectively and quick [9].

- Maximum robots are programmed, so they can perform various undertakings without requiring human connection [10].

- Robots are utilized in various production lines to deliver things like plane, vehicle parts and so on [10].

- They can be utilized for mining purposes As we realize that robots chip away at the program that has been introduced in them. So other than the program introduced, robots can't 
do anything different. The most significant impediment is that if the program of robots comes in wrong hands they can cause the immense measure of demolishment [10].

- As we realize that robots chip away at the program that has been introduced in them. So other than the program introduced, robots can't do anything different. The most significant inconvenience is that if the program of robots comes in wrong hands they can cause destruction as well [10].

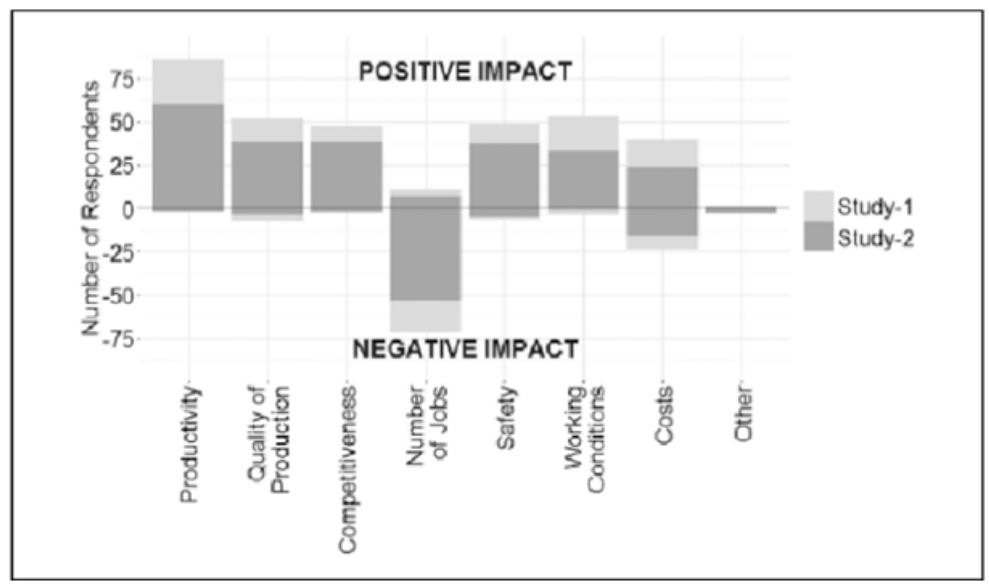

Fig. 3. Imapcts of robotics

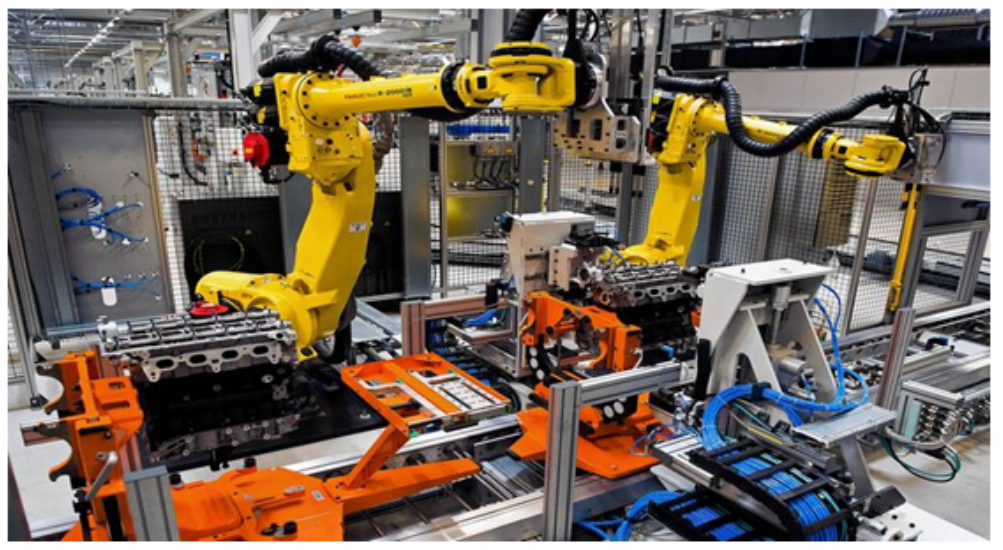

Fig. 4. Industrial view of robotics [11]

\section{SUGGESTIONS}

Since we have research and deeply study about the robotics education and technology. I am of the view that Education system should aware the students about the advancement of robotics engineering so that students well aware about the technology to seek, learn, adapt and explore new ideas for modern day world. Companies should build their strong relation to such robotics engineers so that there will be less unemployment. Furthermore, this is very beneficial for the companies that instead of paying massive amount of salaries they have to just pay for maintenance of robots. Robots in the company will be of any kind using AI or without using it.at the end Quality of work productivity increase.

\section{CONCLUSION}

Various kinds of robots can perform various sorts of assignments. For instance, huge numbers of the robots are made for get together work which implies that they are not pertinent for some other work and these sorts of robots are called Gathering Robots. Likewise, for crease welding numerous providers give robots their welding materials and these sorts of robots are known as Welding Robots. While then again numerous robots are intended for substantial. Obligation work and are known as Rock Solid Robots. There are a couple of utilizations given underneath: Caterpillar plans which is meaning to create remote-controlled machines and are hoping to grow overwhelming robots by 2021. A robot can likewise do Grouping task. Robots are progressively being utilized more than people in assembling while in car industry there are the greater part of the works are "Robots". Many of the robots are utilized as Military Robots. Robots have been utilized in tidying up of regions like lethal waste or mechanical squanders and so on. 
- Agricultural robots [12].

- Household robots [12].

- Domestic robots [12].

- Nano robots [12].

- Swarm robots [12].

\section{ROBOTICS SYSTEM CAUSES UNEMPLOYMENT(YES OR NOT )}

It seems that the Robotics system creates unemployment. But in reality it promotes employment. We all know that there are always two sides of pictures one is black and other is white. This is human nature humanity always think of black side even they know that they are getting advantage from the white side. So the answer of the question is that there are many engineers in Robotics engineering that are unemployed because of less promotion of RIM (Robotics Industrial manufacture) this implementation of Autonomous robotics flourish and promotes the employment Opportunities also promote mutual relation between the foreign companies. The point is quality of work produced in less time this is the biggest advantage of this technology. Also it helps the humans to collaborate in their works.

\section{REFERENCES}

[1] The Conversation, "The new industrial revolution: Robots are an opportunity, not a threat," 2020. [Online]. Available: https://bit.ly/38NKsdM

[2] Frontiers, "Researchers in Japan make android child's face strikingly more expressive," 2018. [Online]. Available: https://bit.ly/32PCzRb

[3] Aci Controls, "The impact of robotic technology in the manufacturing industry," 2018. [Online]. Available: https://bit.ly/3ptkt1j

[4] Frontiers2, "Six degrees of freedom in current robotics research," 2015. [Online]. Available: https://bit.ly/2IvSjSF

[5] Frontiers, "Robotics and AI," 2020. [Online]. Available: https://bit.ly/36IPQvY

[6] International Federation of Robotics, "Brexit: UK falling back in global automation race -robot sales down 3\%," 2019. [Online]. Available: https://bit.ly/3lvJUwC

[7] T. Melanson, "What industry 4.0 means for manufacturers," 2020. [Online]. Available: https://bit.ly/2IIO6Lf

[8] College of Science and Engineering, "Robotics and artificial intelligence," 2020. [Online]. Available: https: //bit.ly/3kuq3g0

[9] Science Daily, “Artificial intelligence news," 2020. [Online]. Available: https://bit.ly/38IQIDH

[10] Daniel Faggella, "Machine learning in robotics-5 modern applications," 2020. [Online]. Available: https://bit.ly/ 2 KcFRaR

[11] Galus Australis, "Global industrial robotics services market 2020 various manufacturing industries: ABB, FANUC, KUKA, Omron adept technologies, remtec automation," 2020. [Online]. Available: https://bit.ly/320aFoV

[12] Robotics Tomorrow, "How artificial intelligence and robotics can create more employment opportunities," 2020. [Online]. Available: https://bit.ly/3lCf8SK 